\title{
Evaluation of highly buffered low-calcium solution for long-term preservation of the heart
}

\section{Comparison with University of Wisconsin solution}

Myocardial preservation for prolonged ischemia has traditionally centered around deep hypothermia with metabolic arrest. This approach is limited in tolerable ischemic time by the state of energy reserves at the onset of ischemia, because anaerobic glycolysis during ischemia is limited by endproduct accumulation (lactate, alanine, and $\mathrm{H}^{+}$). In this study we evaluated a novel preservation solution containing the basic amino acid histidine to buffer $\mathrm{H}^{+}$, glucose as substrate, and low sodium and calcium concentrations to mimic the intracellular ionic environment. Isolated rabbit hearts were subjected to hypothermic ischemia for 8 and 16 hours at $4^{\circ}$ and $21^{\circ} \mathrm{C}$ followed by reperfusion. The buffered solution was compared to University of Wisconsin solution (high potassium). Intracellular pH was maintained at preischemic levels in the buffered solution hearts at $21^{\circ} \mathrm{C}$, and this was associated with better preservation of high energy stores and recovery of contractile function. Developed pressure recovered to $90 \% \pm 3 \%$ of preischemic values after 16 hours of $21^{\circ} \mathrm{C}$ ischemia with the buffered solution as compared with $79 \% \pm 2 \%$ in the University of Wisconsin group at $4^{\circ} \mathrm{C}$ (contracture occurred in the University of Wisconsin hearts at $21^{\circ} \mathrm{C}$ ). The optimal temperature in the buffered solution hearts was $13^{\circ} \mathrm{C}$, and with this temperature acceptable recovery of contractile function was seen after 24 hours of ischemia. On the basis of these results, we conclude that promoting anaerobic glycolysis during ischemia achieves superior prolonged preservation of energetic and contractile function of the heart. (J THORaC CardiovasC SuRG 1994;108:762-71)

Akihiko Ohkado, MD, Hung Cao-Danh, PhD, K. Eric Sommers, MD, and

Pedro J. del Nido, MD, Pittsburgh, $\mathrm{Pa}$.

From the Division of Cardiothoracic Surgery, University of Pittsburgh School of Medicine, and the Pittsburgh NMR Center for Biomedical Research, Carnegie-Mellon University, Pittsburgh, $\mathrm{Pa}$.

This work was supported in part by National Institutes of Health grant R29-HL46207 (Dr. del Nido) and by National Institutes of Health grant 1P41-RR03631 (Pittsburgh NMR Center for Biomedical Research)

Received for publication Dec. 17, 1993.

Accepted for publication May 2, 1994.

Address for reprints: Pedro J. del Nido, MD, Division of Cardiothoracic Surgery, University of Pittsburgh School of Medicine, Rm. 4B-465, Children's Hospital of Pittsburgh, Pittsburgh, PA 15213. Copyright $(2) 1994$ by Mosby-Year Book, Inc.

$0022-5223 / 94 \$ 3.00+0 \quad \mathbf{1 2} / \mathbf{1} / \mathbf{5 7 4 3 6}$
$\mathrm{M}$ yocardial preservation for transplantation in the clinical setting is commonly attained by the use of cardioplegic solutions that rapidly arrest the heart, followed by simple hypothermic storage until reimplantation. The aim is to achieve rapid arrest and profound hypothermia to retard the inevitable metabolic deterioration and loss of high-energy stores that occur during ischemia. More recently, greater emphasis has been placed on preventing cation $\left(\mathrm{Ca}^{++}\right.$and $\mathrm{Na}^{+}$) accumulation in the ischemic myocytes because this process leads to cell swelling, lytic enzyme activation, and contractile protein interaction. ${ }^{1}$ By way of achieving this objective, solutions with low sodium and calcium concentrations 
Table I. Tissue histidine and high-energy phosphates at end-ischemia: Preliminary experiments $(3$ hours of ischemia at $37^{\circ} \mathrm{C}$ )

\begin{tabular}{lccc}
\hline & Preischemic value & Krebs $+K^{+}$ & Krebs $+K^{+}+$histidine \\
\hline Cytosolic histidine $(\mu \mathrm{mol} / \mathrm{gm}$ dry weight) & $0.5 \pm 0.5$ & $3.4 \pm 1$ & $1156 \pm 181^{*} \dagger$ \\
ATP $(\%$ of preischemic value: $5.7 \pm 0.1 \mathrm{mmol} / \mathrm{L})$ & 100 & $59 \pm 4 \dagger$ & $81 \pm 3^{*} \dagger$ \\
Phosphocreatine $(\%$ of preischemic value) & 100 & $8 \pm 1 \dagger$ & $62 \pm 3^{*} \dagger$ \\
Intracellular pH & $7.1 \pm 0.02$ & $6.8 \pm 0.06 \dagger$ & $7.5 \pm 0.05^{*} \dagger$ \\
\hline
\end{tabular}

All values mean \pm standard error; $n=6$ per group.

${ }^{*} p<0.05$ versus $\mathrm{Krebs}+\mathrm{K}^{+}$

$\dagger p<0.05$ versus preischemic value.

along with impermeable anions have been used with improved myocardial protection. ${ }^{2}$ Nevertheless, the concept of metabolic arrest has limited potential for longterm preservation because adenosine triphosphate (ATP) hydrolysis with resultant $\mathrm{H}^{+}$production continues even at temperatures near $0^{\circ} \mathrm{C}^{3}$

During ischemia, the metabolic pathway that is capable of regenerating high-energy phosphates and reoxidizing nicotinamide-adenine dinucleotide (NADH) is anaerobic glycolysis. Glycolytic flux, however, is eventually inhibited during ischemia by the accumulation of end products of anaerobic glycolysis, mainly $\mathrm{H}^{+}$, lactate, and alanine, ${ }^{4}$ along with a finite amount of available substrate (glucose or glycogen). Removing $\mathrm{H}^{+}$by various buffers in an effort to disinhibit glucose metabolism has been shown to increase glycolytic flux during ischemia and lead to enhanced high-energy phosphate preservation and postischemic recovery of contractile function. 5,6 To determine whether promoting anaerobic glycolysis improves cardiac preservation during prolonged ischemia, we formulated a cardioplegic solution containing histidine as a proton buffer with a low sodium and calcium concentration and other additives aimed at preventing cation accumulation in the myocytes during ischemia. The alkaline amino acid histidine was chosen as the buffering agent because of its favorable $\mathrm{pK}\left(6.8\right.$ at $\left.25^{\circ} \mathrm{C}\right)$, lack of toxicity (essential amino acid), and the fact that it is readily transported into the cytosol. Substrate for anaerobic glycolysis was provided in the form of glucose, with insulin added to facilitate glucose transport into the cells. The effects of temperature and multidose administration were also studied and compared with University of Wisconsin (UW) (high-potassium) solution in an isolated rabbit heart preparation subjected to prolonged ischemia.

\section{Material and methods}

Preliminary experiments. Initial experiments were performed to determine the effects of high-dose extracellular histidine $(100 \mathrm{mmol} / \mathrm{L})$ on intracellular histidine concentration, $\mathrm{pH}$, and high-energy phosphate preservation, as well as glyco- lytic end-product (lactate and alanine) production. The results of these preliminary experiments will be shown here. For these and all subsequent isolated heart experiments, New Zealand White rabbits weighing 2 to $3 \mathrm{~kg}$ were anesthetized with ketamine hydrochloride $(50 \mathrm{mg} / \mathrm{kg})$ intravenously. Heparin $(300 \mathrm{U} / \mathrm{kg})$ was given by the same route. The heart was then excised and perfused in a retrograde manner via an aortic cannula at a constant pressure of $80 \mathrm{~cm} \mathrm{H}_{2} \mathrm{O}$ with Krebs-Henseleit bicarbonate buffer gassed with $95 \%$ oxygen and $5 \%$ carbon dioxide and containing an $11 \mathrm{mmol} / \mathrm{L}$ concentration of glucose for substrate with insulin $10 \mathrm{U} / \mathrm{L}$ added. Details of this preparation have been previously described. ${ }^{7}$

In these preliminary experiments, after an initial stabilization period of 30 minutes, perfusion to the hearts was stopped and the hearts were arrested with modified Krebs buffer $(20 \mathrm{ml}$ for a 6 to $7 \mathrm{gm}$ heart) containing potassium chloride $(\mathrm{KCl})$ in a concentration of $20 \mathrm{mmol} / \mathrm{L}$. In the control hearts $\mathrm{KCl}$ buffer was used alone, and in the experimental group histidine in a concentration of $100 \mathrm{mmol} / \mathrm{L}$ was added to the cardioplegic solution. For these preliminary experiments, the hearts were maintained ischemic at $37^{\circ} \mathrm{C}$ for a total of 3 hours during which additional cardioplegic infusions $(20 \mathrm{ml})$ were given hourly. After 3 hours of ischemia the hearts were then reperfused with oxygenated Krebs-Henseleit buffer for 30 minutes. In one group of hearts $(n=6)$ a $50 \mathrm{mg}$ left ventricular sample was obtained before ischemia and at end-ischemia to determine cytosolic histidine concentration. Ventricular tissue samples were homogenized, centrifuged, and the supernatant frozen at $-80^{\circ} \mathrm{C}$. Histidine and alanine assays were done by means of a Waters high-performance liquid chromatography system (Waters Corp., Rochester, Minn.). ${ }^{8}$ In a second group $(n=6)$, high-energy phosphates and intracellular $\mathrm{pH}$ were measured continuously during ischemia and reperfusion with phosphorus 31-nuclear magnetic resonance spectroscopy (see ${ }^{31} P-N M R$ measurements in the Methods section). Lactate and alanine production during ischemia was measured from tissue and coronary effluent (cardioplegia). ${ }^{9}$

The cytosolic histidine concentrations, high-energy phosphates (phosphocreatine and ATP), and intracellular $\mathrm{pH}$ for both the $\mathrm{KCl}$ and $\mathrm{KCl}+$ histidine groups are shown in Table I. The production of anaerobic glycolysis end products, lactate and alanine, in these two groups of hearts is shown in Fig. 1. Recovery of contractile function was better in the group receiving Krebs + histidine cardioplegia with developed pressure returning to $86 \% \pm 5 \%$ of the preischemic pressure versus $73 \% \pm 4 \%$ for the Krebs $+\mathrm{K}^{+}$group $(p<0.05)$. On the basis of these preliminary studies, we concluded that histidine, when provided in a high extracellular concentration $(100 \mathrm{mmol} / \mathrm{L}),(1)$ 


\section{TOTAL LACTATE PRODUCTION}

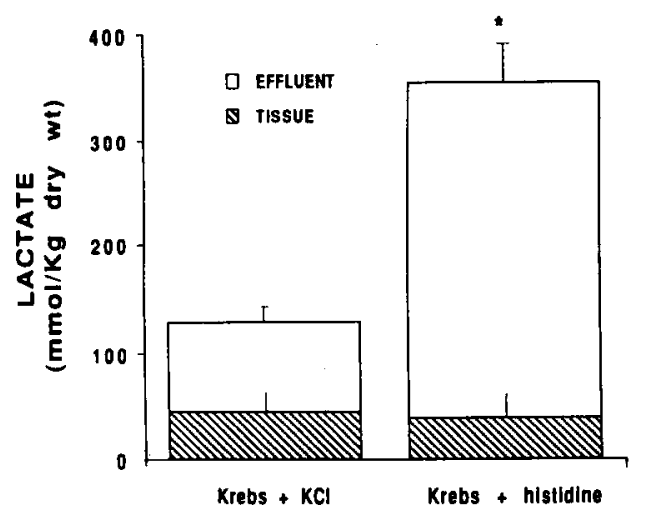

TOTAL ALANINE PRODUCTION

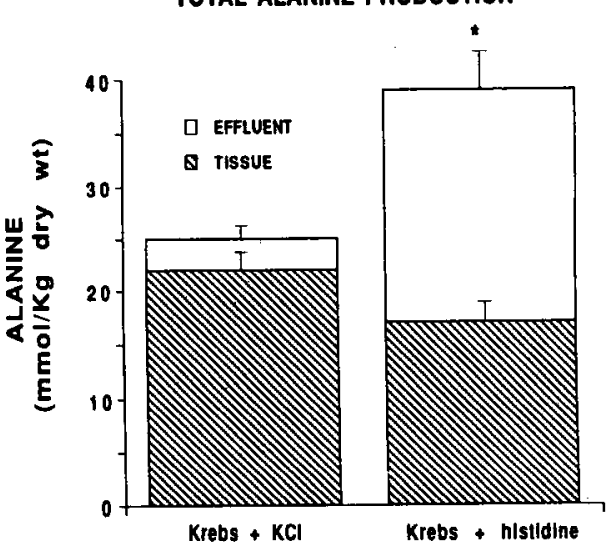

Fig. 1. Preliminary experiments. Tissue concentrations and release of the glycolytic end products lactate and alanine during ischemia. $\left({ }^{*} p<0.05\right.$ for total production in the $\mathrm{Krebs}+$ histidine versus the $\mathrm{Krebs}+\mathrm{KCl}$ treated hearts.)

can readily enter the cytosol of myocardium, (2) can buffer intracellular $\mathrm{pH}$ at preischemic levels even during normothermic ischemia, and (3) can increase the production of glycolytic end products, suggesting a greater glycolytic flux during ischemia. The $\mathrm{pH}$ buffering effects of histidine were associated with superior high-energy phosphate preservation during ischemia.

A novel cardioplegic solution was then formulated by lowering the sodium and calcium concentrations and using glucose with insulin as substrate; lidocaine and adenosine were also added. The cardioplegic solution was given at the onset of ischemia and in the moderate hypothermia groups, as hourly flushes during the entire ischemic period. This new formulation was then compared with the UW solution in a model of hypothermic prolonged ischemia.

Preservation solutions. The composition of the histidinebuffered and UW solutions is shown in Table II. These formulations were used for all subsequent experiments with prolonged hypothermic ischemia. Both solutions contain low sodium and elevated potassium concentrations, although the UW solution is formulated similar to intracellular conditions. Both contain low or no calcium and elevated magnesium concentrations. $\mathrm{Ca}^{++}$ $0.1 \mathrm{mmol} / \mathrm{L}$ was added to the buffered solution because calcium paradox has been shown to occur with histidine buffering in the absence of calcium. ${ }^{10} \mathrm{H}^{+}$buffering was achieved in the buffered solution with a $100 \mathrm{mmol} / \mathrm{L}$ concentration of histidine hydrochloride at a $\mathrm{pH}$ of 7.8, whereas in the UW solution some buffering is attained by the addition of phosphates. Substrate for glycolysis is provided by glucose with insulin in the buffered solution and none in UW solution. Lidocaine hydrochloride was also added to the buffered solution to block sodium channel activity and thus delay depolarization of the myocytes and retard entry of sodium into the cytosol. ${ }^{11}$ Adenosine is present in both solutions in high concentration ( 5 to $6 \mathrm{mmol} / \mathrm{L}$ ) primarily to delay rapid breakdown of high-energy nucleotides into the more soluble nucleosides and to prevent loss of soluble nucleosides with the intermittent flushes of cardioplegic solution during ischemia. ${ }^{12}$

Animal preparation. An isolated Langendorff crystalloidperfused rabbit heart preparation was used for these experiments, as $w^{7}$ have previously described. Hearts that did not attain a stable heart rate greater than $2 \mathrm{~Hz}$ or had arrhythmias were discarded. After an initial stabilization period of $30 \mathrm{~min}-$ utes, hypothermic ischemia was induced with an infusion of arresting solution $(20 \mathrm{ml}$, with an average heart weight of $7 \pm 1$ $\mathrm{gm}$ ) given over 2 minutes. At the end of the ischemic period ( 8 or 16 hours), reperfusion was started at $37^{\circ} \mathrm{C}$ at the same perfusion pressure as before ischemia and was continued for 30 minutes. Contractile function was measured at the end of the preischemic stabilization period and after 30 minutes of reperfusion. ${ }^{31} \mathrm{P}-\mathrm{NMR}$ measurements were obtained before ischemia and at the end of ischemia.

Contractile function and coronary flow. Myocardial contractile function was measured with a latex fluid-filled balloon inserted into the left ventricle and fixed to the mitral anulus to prevent ejection. The balloon was connected to a catheter-tipped high-fidelity pressure transducer (Millar Instruments, Inc., Houston, Tex.) to measure intracavitary pressures. The balloon was constructed to have a volume large enough so that no pressure was generated when filled to the volume range used in the experiments $(<1 \mathrm{ml})$. During functional assessments, the balloon was filled with distilled water from a calibrated syringe to permit incremental volume changes with simultaneous pressure measurements. Systolic and diastolic pressure was recorded with a balloon volume that yielded a preischemic diastolic pressure of 8 to $10 \mathrm{~mm} \mathrm{Hg}$, and the same balloon volume was used for the reperfusion measurements. The balloon was emptied and left in situ during ischemia. Diastolic pressure just before ischemia and after 30 minutes of reperfusion was recorded and developed pressure was calculated. After ischemia, contractile measurements were recorded when a stable rhythm ( $>10$ beats) was obtained after 30 minutes of reperfusion. Peak developed pressure after reperfusion was expressed as percent recovery of the preischemic value for each heart.

Coronary flow was measured by timed collection of the right ventricular effluent, with the right atrium sewn closed, just before functional measurements with the balloon filled, and the value was expressed as percent recovery of preischemic flow.

Total tissue water content was also measured at the end of the reperfusion period. After the biventricular mass was excised and weighed, it was placed in a $150^{\circ} \mathrm{C}$ oven and dried to a constant 
Table II. Composition of cardioplegic solutions

\begin{tabular}{|c|c|c|}
\hline & $\begin{array}{l}\text { Buffered } \\
\text { solution }\end{array}$ & $\begin{array}{c}\text { UW } \\
\text { solution }\end{array}$ \\
\hline $\mathrm{Na}^{+}(\mathrm{mmol} / \mathrm{L})$ & 80.0 & 20.0 \\
\hline $\mathrm{K}^{+}(\mathrm{mmol} / \mathrm{L})$ & 22.5 & 140.0 \\
\hline $\mathrm{Mg}^{2+}(\mathrm{mmol} / \mathrm{L})$ & 6.0 & 5.0 \\
\hline $\mathrm{Ca}^{2+}(\mathrm{mmol} / \mathrm{L})$ & 0.1 & 0 \\
\hline $\mathrm{PO}_{4}^{2-}(\mathrm{mmol} / \mathrm{L})$ & 2.5 & 25.0 \\
\hline Glucose (mmol/L) & 11.0 & 0 \\
\hline Insulin $(\mathrm{IU} / \mathrm{L})$ & 10.0 & 100.0 \\
\hline Mannitol (mmol/L) & 20.0 & 0 \\
\hline Histidine $\mathrm{HCl}(\mathrm{mmol} / \mathrm{L})$ & 100.0 & 0 \\
\hline Adenosine $(\mathrm{mmol} / \mathrm{L})$ & 5.0 & 5.0 \\
\hline Lidocaine (mg/L) & 100.0 & 0 \\
\hline Lactobionate $(\mathrm{mmol} / \mathrm{L})$ & 0 & 100.0 \\
\hline Raffinose (mmol/L) & 0 & 30.0 \\
\hline Hydroxyethyl starch (\%) & 0 & 5.0 \\
\hline Glutathione (mmol/L) & 0 & 3.0 \\
\hline Allopurinol (mmol/L) & 0 & 1.0 \\
\hline Heparin (IU/L) & 0 & 1000.0 \\
\hline $\mathrm{pH}$ & 7.8 & $7.2-7.3$ \\
\hline Osmolarity $(\mathrm{mOsm} / \mathrm{L})$ & 340 & 300 \\
\hline
\end{tabular}

weight for 4 hours to determine myocardial water content according to the formula:

$$
\cdot 1-\text { (Dry weight/Wet weight) } \times 100
$$

${ }^{31} P$-NMR measurements. ${ }^{31} \mathrm{P}-\mathrm{NMR}$ spectra of the hearts were obtained with a $4.7 \mathrm{~T}$ Bruker Biospec spectrometer (Bruker Medical Instruments, Inc., Billerica, Mass.) in a $40 \mathrm{~cm}$ bore superconducting magnet operating at a ${ }^{31} \mathbf{P}$ frequency of 81 $\mathrm{MHz}$. During spectral measurements, hearts were immersed in a perfusion chamber surrounded by a $3.1 \mathrm{~cm}$ diameter, five-turn solenoid coil. A bulb containing dimethylene phosphonic acid as an internal standard was placed in the right ventricle. Ninetydegree radiofrequency pulses were applied with a recycle time of 2 seconds. Data were acquired for 5 minutes for a total of 148 acquisitions per spectrum. Two spectra were obtained just before and at the end of the ischemic period. Concentration measurements of each of the phosphorus-containing metabolites were obtained by integration of the area under the individual peaks.

Phosphocreatine and ATP concentrations were expressed as a percent of the preischemic area. Quantitation of high-energy phosphate compounds was done in a separate group of 22 hearts before ischemia with high-performance liquid chromatography. ${ }^{13}$ Samples were obtained by freeze clamping $(100 \mathrm{mg})$ of the heart at the end of the preischemic stabilization period and just after NMR spectra were obtained. The samples were weighed, powderized under liquid nitrogen in 5 volumes of $4 \%$ perchloric acid, and the homogenate was centrifuged for 10 minutes at 15,000 rpm, decanted, neutralized with tetraethylammonium, centrifuged again, and the supernatant stored at $-80^{\circ} \mathrm{C}$. A Waters 600 high-performance liquid chromatography delivery pump, ultraviolet spectrometer detector, and Whatman Partisil-10-SAX anion exchange column (Whatman, Inc., Clifton, N.J.) were used for ATP and phosphocreatine assays. ${ }^{14}$ ATP and phosphocreatine were expressed as cyto-
Table III. Recovery of coronary flow after reperfusion

\begin{tabular}{ccc}
\hline & \multicolumn{2}{c}{ Flow (\% of preischemic value) } \\
\cline { 2 - 3 } & $\begin{array}{c}\text { Buffered } \\
\text { solution }\end{array}$ & $\begin{array}{c}\text { UW } \\
\text { solution }\end{array}$ \\
\hline $8 \mathrm{hr}$ ischemia & & \\
$4^{\circ} \mathrm{C}$ & $96 \pm 3 \%$ & $84 \pm 3 \%^{*}$ \\
$21^{\circ} \mathrm{C}$ & $101 \pm 5$ & $66 \pm 4^{*}$ \\
$16 \mathrm{hr}$ ischemia & $92 \pm 7 \%$ & $77 \pm 5 \%^{*}$ \\
$4^{\circ} \mathrm{C}$ & $156 \pm 48^{*}$ & - \\
$13^{\circ} \mathrm{C}$ & $99 \pm 5$ & - \\
$21^{\circ} \mathrm{C}$ & $108 \pm 14 \%$ & - \\
$20 \mathrm{hr}$ ischemia & & - \\
$13^{\circ} \mathrm{C}$ & $106 \pm 12 \%$ & - \\
$24 \mathrm{hr}$ ischemia & $13^{\circ} \mathrm{C}$ & \\
\hline
\end{tabular}

All values mean \pm standard error; $n=6$ or 7 per group.

${ }^{*} p<0.05$ versus preischemic values.

Table IV. High-energy phosphates and intracellular pH at end-ischemia (8 hours)

\begin{tabular}{ccc}
\hline $\begin{array}{c}\text { Buffered } \\
\text { solution }\end{array}$ & $\begin{array}{c}\text { UW } \\
\text { solution }\end{array}$ \\
\hline ATP (mmol/L): Preischemic value & $5.9 \pm 0.2 \mathrm{mmol} / \mathrm{L}$ \\
$4^{\circ} \mathrm{C}^{\circ}$ & $2.8 \pm 0.3^{*}$ & $3.6 \pm 0.3^{*}$ \\
$21^{\circ} \mathrm{C}$ & $4.7 \pm 0.3^{*}$ & - \\
Phosphocreatine (\% of preischemic value) & \\
$4^{\circ} \mathrm{C}$ & $11 \pm 2^{*}$ & $12 \pm 1^{*}$ \\
$21^{\circ} \mathrm{C}$ & $62 \pm 8^{*}$ & - \\
Intracellular pH: Preischemic value $7.10 \pm 0.02$ & \\
$4^{\circ} \mathrm{C}$ & $6.54 \pm 0.07^{*}$ & $6.50 \pm 0.05^{*}$ \\
$21^{\circ} \mathrm{C}$ & $7.15 \pm 0.03^{*} \dagger$ & - \\
\hline
\end{tabular}

All values mean \pm standard error; $n=6$ per group.

${ }^{*} p<0.05$ versus preischemic value.

$+p<0.05$ versus UW solution.

solic concentration using the wet/dry ratio and assuming nonmitochondrial cytosolic volume as $40 \%$. ${ }^{15}$

Intracellular $\mathrm{pH}$ was determined from the chemical shift of the inorganic phosphate peak relative to that of phosphocreatine by means of the formula:

$$
\mathrm{pH}=6.75+\log (\delta-3.27 / 5.69-\delta)
$$

where $\delta$ is the chemical shift difference in parts per million between inorganic phosphate and phosphocreatine. ${ }^{13}$ For the preischemic measurements, phosphate was omitted from the Krebs perfusate to facilitate intracellular $\mathrm{pH}$ determination.

Comparison experiments (buffered versus UW solution).

Experimental groups. Four different groups of hearts were evaluated with 8 and 16 hours of ischemia followed by 30 minutes of reperfusion. Contractile function, coronary flow, and water content were measured in these four groups. Two groups received the buffered solution. One group received a single infusion of cardioplegic solution at $4^{\circ} \mathrm{C}$ at the onset of ischemia followed by simple immersion at $4^{\circ} \mathrm{C}$, and the second 


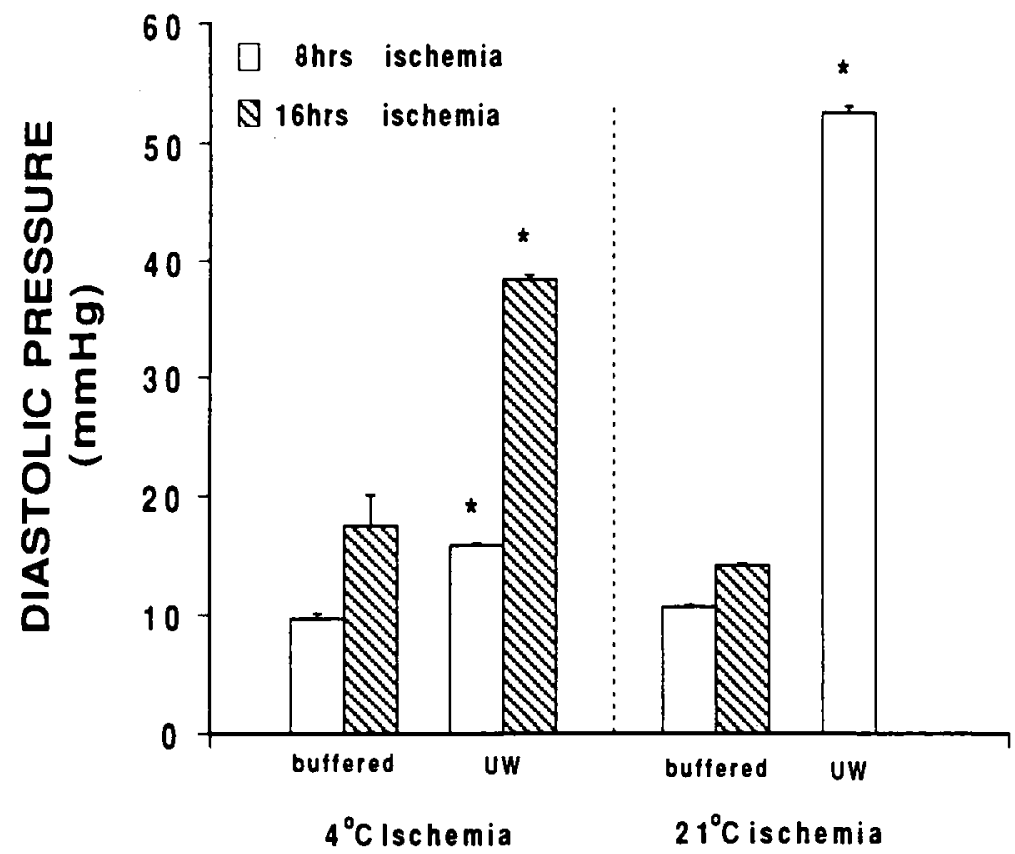

Fig. 2. Comparison experiments (buffered versus UW solution). Left ventricular diastolic pressure measured with an intracavitary balloon 30 minutes after reperfusion. The same balloon volume that generated a diastolic pressure of $8 \pm 1 \mathrm{~mm} \mathrm{Hg}$ before ischemia was used for the postischemic measurements. ( ${ }^{*} p<0.05$ versus the buffered solution group.)

received the cardioplegic solution at $21^{\circ} \mathrm{C}$ with an infusion at the onset of ischemia followed by hourly infusions $\left(21^{\circ} \mathrm{C}\right)$ with the same volume of solution given over 2 minutes. UW solution was administered to the other two groups following the same protocol as with the buffered solution. During ischemia, constant temperature was maintained by placing the hearts in a temperature-controlled environment at either $4^{\circ}$ or $21^{\circ} \pm 1^{\circ}$ $\mathrm{C}$. Thus no ice was used in the $4^{\circ} \mathrm{C}$ simple immersion group.

ATP, phosphocreatine, and intracellular $\mathrm{pH}$ were measured with ${ }^{31} \mathrm{P}-\mathrm{NMR}$ spectroscopy in a separate group of hearts subjected to ischemia at $4^{\circ}$ and $21^{\circ} \mathrm{C}$ with the buffered solution and at $4^{\circ} \mathrm{C}$ with UW solution.

Statistical analysis. Comparisons between groups were done with analysis of variance for repeated measures, and comparisons within each group were analyzed with paired $t$ tests. All values are expressed as mean plus or minus standard error of the mean and a $p$ value less than 0.05 was considered significant.

All animals received humane care in compliance with the "Guide for the Care and Use of Laboratory Animals" published by the National Institutes of Health (NIH publication No. 85-23, revised 1985).

\section{Results} tion)

Comparison experiments (buffered versus UW solu-

Contractile function. Postischemic diastolic pressure measured at the same balloon volume for 8 and 16 hours of ischemia is shown in Fig. 2. With 8 hours of ischemia at $4^{\circ} \mathrm{C}$ with a single infusion of preservation solution followed by simple immersion, the UW group exhibited a small but significant rise in diastolic pressure after reperfusion, which was not seen in the buffered solution group. At $21^{\circ} \mathrm{C}$ with hourly cardioplegic infusions, there was no significant change in diastolic pressure in the hearts receiving the buffered solution, whereas ischemic contracture developed by 8 hours of ischemia in the group receiving $U W$ solution. For this reason a 16-hour $21^{\circ} \mathrm{C}$ ischemia group was not done with UW solution. With 16 hours of ischemia, both buffered solution groups demonstrated a small but significant rise in diastolic pressure. However, ischemic contracture had developed by the end of ischemia in the UW group of hearts at $4^{\circ} \mathrm{C}$.

Postischemic developed pressure after 8 and 16 hours of ischemia and 30 minutes of reperfusion in all groups is shown in Fig. 3. With 8 hours of $4^{\circ} \mathrm{C}$ ischemia there was a small difference in recovery between the buffered and UW-treated hearts, with good preservation of contractile function in both groups. With 16 hours of ischemia at $4^{\circ}$ $C$ there was significantly better preservation of contractile function in the hearts receiving the buffered preservation solution when compared with the UW group, in which recovery was limited because of the onset of con- 


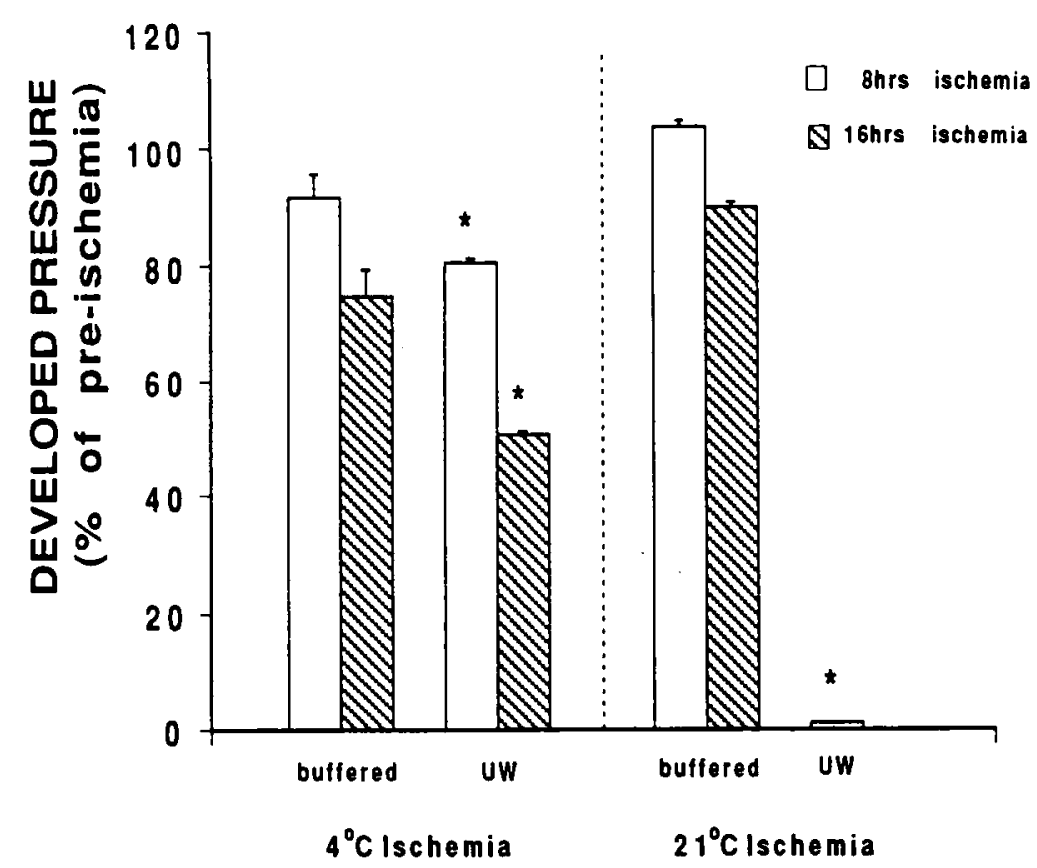

Fig. 3. Comparison experiments (buffered versus UW solution). Left ventricular developed pressure after 30 minutes of reperfusion measured at the same balloon volume as before ischemia. The results are expressed as percent of preischemic developed pressure for each heart. $\left({ }^{*} p<0.05\right.$ versus the buffered solution group.)

tracture. The hearts receiving buffered solution hourly at $21^{\circ} \mathrm{C}$, however, demonstrated excellent recovery after both 8 and 16 hours of ischemia with nearly complete return of developed pressure after 30 minutes of reperfusion.

Coronary flow and tissue water content. Recovery of coronary flow after 30 minutes of reperfusion (expressed as percent of preischemic flow) for all groups is shown in Table III. Postischemic coronary flow returned to preischemic values in the hearts receiving buffered solution and appeared to parallel the postischemic diastolic pressure changes in all groups.

${ }^{3 l} P$-NMR measurements. ATP and phosphocreatine concentrations and intracellular $\mathrm{pH}$ measured before and at the end of 8 hours of ischemia are shown in Table IV. High-energy phosphate measurements were not done in the UW hearts at $21^{\circ} \mathrm{C}$ ischemia because ischemic contracture developed in all these hearts by 8 hours. There was a significant decline in ATP concentration in all groups at the end of the 8 hours of ischemia when compared with preischemic values. However, ATP was substantially better preserved in the hearts receiving the buffered solution hourly at $21^{\circ} \mathrm{C}$ when compared with both the UW and buffered solution groups with $4^{\circ} \mathrm{C}$ ischemia. Similarly, phosphocreatine concentration declined in all groups by end-ischemia but was best pre- served in the $21^{\circ} \mathrm{C}$ buffered solution group. Intracellular $\mathrm{pH}$ also fell markedly in both the UW and buffered solution groups at $4^{\circ} \mathrm{C}$ but was maintained at preischemic values in the group receiving multidose buffered solution at $21^{\circ} \mathrm{C}$.

To determine whether multidosing of the buffered solution at $4^{\circ} \mathrm{C}$ conferred any additional protection when compared with a single dose, we studied a separate group of hearts with the same ischemic time but infused the buffered solution hourly at $4^{\circ} \mathrm{C}$. Although intracellular $\mathrm{pH}$ was maintained high, there was no beneficial effect of multidosing the buffered solution at $4^{\circ} \mathrm{C}$ on ATP or phosphocreatine preservation during ischemia. Contractile function was also poorly preserved in this group (data not shown).

Optimal ischemic temperature (buffered solution). In a separate group of hearts, further experiments were performed to determine the optimal temperature for myocardial preservation using the histidine-containing solution. Hearts were subjected to 16 hours of hypothermic ischemia at $4^{\circ}, 13^{\circ}$, and $21^{\circ} \mathrm{C}$. Hourly doses of cardioplegic solution infused in the same manner as previously described were given to the $13^{\circ}$ and $21^{\circ} \mathrm{C}$ ischemia groups. A single dose followed by simple immersion was used in the $4^{\circ} \mathrm{C}$ group because we had already shown that multidosing cardioplegia at this temperature resulted in 
Table V. Postischemic (16 hours) contractile function and coronary flow with buffered solution: Optimal ischemic temperature (buffered solution) after 30 minutes of reperfusion

\begin{tabular}{|c|c|c|c|c|}
\hline \multirow[b]{2}{*}{ Ischemic temperature } & \multicolumn{2}{|c|}{ Diastolic pressure $(\mathrm{mm} \mathrm{Hg})$} & \multirow{2}{*}{$\begin{array}{c}\text { Developed pressure } \\
\text { (\% of preischemic value) }\end{array}$} & \multirow{2}{*}{$\begin{array}{c}\text { Coronary flow } \\
\text { (\% of preischemic value }\end{array}$} \\
\hline & Preischemic & Postischemic & & \\
\hline $4^{\circ} \mathrm{C}$ & $8.5 \pm 0.3$ & $17.5 \pm 2.6^{*}$ & $75 \pm 5^{*}$ & $92 \pm 7$ \\
\hline $13^{\circ} \mathrm{C}$ & $8.6 \pm 0.8$ & $9.4 \pm 0.8$ & $99 \pm 4$ & $123 \pm 13$ \\
\hline $21^{\circ} \mathrm{C}$ & $9.0 \pm 0.3$ & $14.2 \pm 1.1^{*}$ & $90 \pm 3$ & $99 \pm 5$ \\
\hline
\end{tabular}

All values mean \pm standard error; $n=6$ per group

${ }^{*} p<0.05$ versus preischemic value.

worse recovery than a single dose. The results of the high-energy phosphate measurements are shown in Fig. 4 and the contractile function measurements in Table $\mathrm{V}$. The best results were obtained at $13^{\circ} \mathrm{C}$ ischemia with multidose cardioplegia; in this group nearly complete recovery of high-energy phosphates and systolic and diastolic function were observed after 16 hours of ischemia and 30 minutes of reperfusion.

Maximum ischemic time (buffered solution). To determine the maximal length of reversible ischemia in this model, we subjected two additional groups of hearts to 20 and 24 hours of ischemia followed by reperfusion. During ischemia the hearts were maintained at $13^{\circ} \mathrm{C}$ with hourly cardioplegic infusions because this condition was determined to be optimal for preservation. Fig. 5 shows the results of these experiments. Developed pressure recovered to acceptable levels in the 24-hour ischemia group of hearts, but diastolic pressure was significantly elevated.

\section{Comment}

Prolonged cardiac ischemia with organ storage for transplantation presents a unique problem. Whereas in other organs, such as liver and kidney, ATP concentration may fall to low levels without necessarily leading to irreversible ischemic injury, this is not the case in the heart. In myocardium there appears to be a minimum threshold level of ATP required to prevent interaction of the contractile proteins and rigor bond formation leading to irreversible ischemic contracture. ${ }^{16}$ Traditional approaches to myocardial protection have relied on arresting metabolism by contractile arrest and deep hypothermia to preserve energy stores and minimize cation accumulation in myocytes. However, when the ischemic period is prolonged, even the reduced rate of ATP depletion afforded by hypothermia is not sufficient to maintain myocyte viability. In this study we have shown that promoting anaerobic metabolism by moderate hypothermia $\left(13^{\circ}\right.$ to $\left.21^{\circ} \mathrm{C}\right)$, removal of end products by proton buffering and multidose infusions, and providing a substrate (glucose with insulin) produce superior preservation of high-energy phosphates and recovery of contractile function despite prolonged ischemia.

Glycolysis in the heart. In the oxygenated perfused heart, glycolysis is not believed to be a significant source of high-energy compounds because the Krebs cycle in mitochondria is so much more efficient in ATP production. ${ }^{17}$ Indeed, the preferred substrate in the bloodperfused heart is fatty acids with glucose accounting for less than $20 \%$ of oxygen consumption in the working heart. ${ }^{18}$ Nevertheless, there is a growing body of evidence that suggests that glycolysis may have an important role in supplying ATP for the membrane ion pumps and thus may serve an important role in maintaining intracellular ionic homeostasis. ${ }^{19}$ Also, during early reperfusion after an ischemic insult, glycolysis has been shown to play a crucial role in recovery of contractile function. ATP generated from glycolysis appears to be preferentially used by ion pumps in the sarcolemma and sarcoplasmic reticulum during this critical time. ${ }^{20}$

During ischemia, anaerobic glycolysis is the only potential source of ATP because oxidative phosphorylation is rapidly inhibited by lack of oxygen and accumulation of nicotinamide-adenine dinucleotide (NADH) in the mitochondria. Inhibition of glycolytic flux has been temporally associated with the onset of contracture in ischemic hearts, and chemical inhibition of glycolysis is associated with an earlier onset of contracture. ${ }^{21}$ Glycolysis under anaerobic conditions may therefore serve not only to generate high-energy phosphates but also to regenerate nicotinamide-adenine dinucleotide $\left(\mathrm{NAD}^{+}\right)$ by the production of lactate or, alternatively, alanine and malate with glutamate and aspartate used as cosubstrates. However, under conditions of total ischemia, accumulation of the glycolytic end products and elevation of $\mathrm{H}^{+}$concentration leads to inhibition of several enzymes in the glycolytic pathway. ${ }^{4}$ Lactate and alanine are both readily diffusible out of the cell and thus can be rapidly removed by perfusion of the ischemic tissue. $\mathrm{H}^{+}$removal from the cell, however, requires either co-transport with an anionic compound such as lactate or, most commonly, $\mathrm{H}^{+}$exchange for extracellular $\mathrm{Na}+$ by the electroneutral 


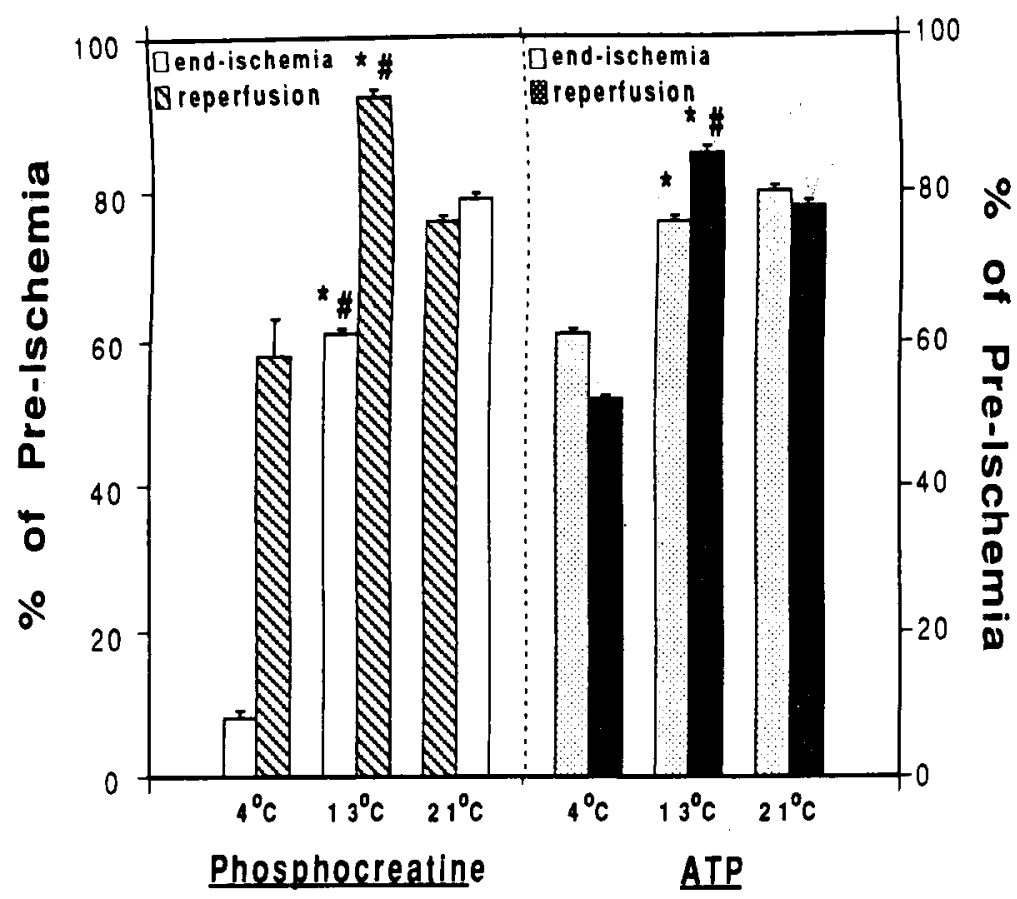

Fig. 4. Optimal ischemic temperature (buffered solution). Tissue ATP and phosphocreatine concentrations at the end of 16 hours of ischemia and after 30 minutes of reperfusion (expressed as percent of the preischemic concentration). ( ${ }^{*} p<0.05$ for $13^{\circ} \mathrm{C}$ versus $4^{\circ} \mathrm{C}$ ischemia group; $\# p<0.05$ for $13^{\circ} \mathrm{C}$ versus $21^{\circ} \mathrm{C}$ ischemia group.)
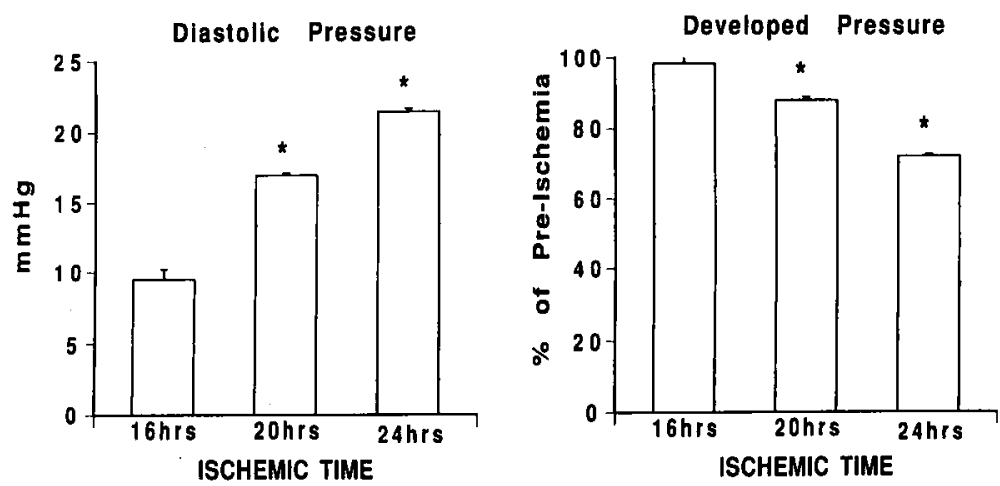

Fig. 5. Maximal ischemic time (buffered solution). Left ventricular diastolic (left) and developed pressure (right) measured after 30 minutes of reperfusion after different ischemic times. All hearts received hourly infusions of buffered solution at $13^{\circ} \mathrm{C}$. Intracavitary balloon volume during the reperfusion measurements was maintained the same as before ischemia. ( ${ }^{*} p<0.05$ versus the 16 -hour ischemia group.)

sodium/hydrogen exchanger on the cell membrane. In the myocyte, the sodium/hydrogen exchanger is active and is considered to be the major mechanism responsible for maintaining intracellular $\mathrm{pH}$ within a tightly controlled range. ${ }^{22}$ However, during ischemia the activity of the sodium/hydrogen exchanger can lead to sodium accumulation in the cell because of the increased intracellular $\mathrm{H}^{+}$concentration. If the sodium-potassium ATPase is inactive, a rise in cytosolic sodium concentration can then lead to a rise in cytosolic calcium concen- tration by the action of the sodium/calcium exchanger on the cell membrane. ${ }^{20}$ Thus, the ideal method of removing $\mathrm{H}^{+}$during ischemia to prevent this cascade of ionic fluxes is by buffering the cation inside the cell to prevent its exchange for extracellular sodium or by removing it with an anion such as lactate or alanine.

$\mathrm{H}^{+}$buffering with histidine. Bretschneider proposed a method for promoting anaerobic glycolysis in the heart during ischemia by providing a high concentration of the basic amino acid L-histidine. ${ }^{23}$ Histidine is a potent pro- 
ton buffer at physiologic $\mathrm{pH}\left(\mathrm{pKa}=6.8\right.$ at $25^{\circ} \mathrm{C}$ ) and is the amino acid most responsible for the intrinsic intracellular buffering capacity. Its ability to readily enter the cell and maintain its excellent buffering capacity, even at low temperatures, makes it an ideal agent to maintain intracellular $\mathrm{pH}$ at normal levels during ischemia. ${ }^{24}$ The presence of a high histidine concentration outside the cell may also be beneficial because it facilitates $\mathrm{H}^{+}$removal from the cytosol by anionic carriers such as lactate. Additional beneficial effects of histidine may also be due to its ability to bind calcium, which has been shown to rise in the cytosol during ischemia. ${ }^{25}$

Optimal ischemic temperature. Considerable controversy remains regarding the optimal temperature for cardiac preservation during ischemia. Whereas general agreement exists that hypothermia is beneficial by lowering of the metabolic rate, severe hypothermia $\left(<4^{\circ} \mathrm{C}\right)$ has been found to lead to cell damage, particularly on reperfusion. Moderate hypothermia $\left(4^{\circ}\right.$ to $21^{\circ} \mathrm{C}$ ), however, has been shown to delay high-energy phosphate depletion with superior protection achieved at the lower temperatures. ${ }^{26}$ The explanation for this finding has been that enzyme activity and transmembrane ion flux is progressively inhibited as temperature is lowered. We hypothesized that this inhibitory effect of hypothermia is detrimental for anaerobic glycolysis because it may impair glycolytic enzyme activity and substrate flux across the cell membrane. Our results varying temperature during prolonged ischemia support this hypothesis, because optimal preservation of high-energy phosphates and recovery of contractile function was achieved at $13^{\circ} \mathrm{C}$. Of interest is the finding that at $4^{\circ} \mathrm{C}$ ischemia, ATP levels and recovery of contractile function were similar between the buffered solution and UW solution groups. Also, in the histidine group, ATP preservation was better at $13^{\circ}$ $\mathrm{C}$ than at $4^{\circ} \mathrm{C}$ despite the fact that intracellular $\mathrm{pH}$ was maintained elevated in the $4^{\circ} \mathrm{C}$ histidine-buffered group. The most likely explanation for the improved preservation at $13^{\circ} \mathrm{C}$ is that glycolytic flux was higher at $13^{\circ} \mathrm{C}$ than at $4^{\circ} \mathrm{C}$. Also, the relatively good results with $21^{\circ} \mathrm{C}$ ischemia demonstrate that there is a significant range in temperatures when the buffered solution is effective. Thus significant protection may still be afforded in situations in which the hearts have rewarmed, such as during the reimplantation procedure in heart transplantation.

Cytosolic cation accumulation. Cytosolic sodium and calcium levels are maintained very low in the myocyte by several mechanisms including ATP-dependent pumps and cation exchangers. During ischemia, both sodium and calcium levels rise in the cytosol and are associated with damage to the cell and eventually lead to irreversible injury. ${ }^{25}$ For long-term preservation, maintaining low extracellular sodium and calcium has been shown to yield improved preservation in different organs, including the heart. In the heart, however, an important source of calcium that is able to leak into the cytosol comes from the large stores present in the sarcoplasmic reticulum. ${ }^{25}$ Perfusion of the heart with a low calcium solution can significantly deplete the calcium stores of the sarcoplasmic reticulum such that cytosolic calcium accumulation during ischemia can be prevented. ${ }^{7}$ For this reason, our preservation solution contained only enough calcium to prevent calcium paradox. Lidocaine was also added to block fast sodium channel activity, because at the warmer temperatures $\left(21^{\circ} \mathrm{C}\right)$ this channel can be activated by the depolarizing effects of high extracellular potassium. Adenosine present in the solution will also augment the effects of lidocaine on the sodium channels, further preventing sodium accumulation in the cytosol.

Finally, even though we can conclude, on the basis of these experiments, that a histidine-containing preservation solution can significantly prolong the safe ischemic time, an important caveat should be stated relating to extrapolating these results to a blood-perfused or reperfused system. Although during ischemia we would expect little or no effects on our results (high-energy phosphates), reperfusion with modified or whole blood may alter the recovery of cardiac function, particularly with the maximal ischemic time experiments. On the basis of subsequent work with blood-perfused piglet hearts, however, we would speculate that the results of the comparison experiments between the buffered and UW solutions would remain largely unchanged.

\section{REFERENCES}

1. Belzer FO, Southard JH. Principles of solid-organ preservation by cold storage. Transplantation 1988;45:6736.

2. Swanson DK, Pasaoglu I, Berkoff HA, Southard JA, Hegge JO. Improved heart preservation with UW preservation solution. J Heart Transplant 1988;7:456-67.

3. Stringham JC, Southard JH, Hegge J, et al. Limitations of heart preservation by cold storage. Transplantation 1992;53:287-94.

4. Rovetto MJ, Lamberton WF, Neely JR. Mechanisms of glycolytic inhibition in ischemic rat hearts. Circ Res 1975;37:742-51.

5. del Nido PJ, Wilson GJ, Mickle DAG, et al. The role of cardioplegia solution buffering in myocardial protection. $\mathbf{J}$ THORAC CARDIOVASC SURG 1985;89:689-99.

6. Bernard M, Menasche $P$, Canioni $P$, et al. Influence of the $\mathrm{pH}$ of cardioplegic solutions on intracellular $\mathrm{pH}$, high-energy phosphates, and postarrest performance. J THORAC Cardiovasc Surg 1985;90:235-42.

7. Jimenez E, del Nido PJ, Sarin M, et al. Effects of low 
extracellular calcium on cytosolic calcium and ischemic contracture. J Surg Res 1990;49:252-5.

8. Daniel $\mathrm{H}$, Morse EL, Adibi SA. The high and low affinity transport systems for dipeptides in kidney brush border membrane respond differently to alterations in $\mathrm{pH}$ gradient and membrane potential. J Biol Chem 1991;266:1991724.

9. Bernt $E$, et al. In Bergmeyer V, ed. Methods of enzymatic analysis. Vol 4. New York: Academic Press, 1972:1772-6.

10. Rebeyka JM, Axford-Gatley RA, Bush BG, et al. Calcium paradox in an in vivo model of multidose cardioplegia and moderate hypothermia: prevention with diltiazem or trace calcium. J THORAC CARdIOVASC SURG 1990;99:475-83.

11. Bean BP, Cohen CJ, Tsien RW. Lidocaine block of cardiac sodium channels. J Gen Physiol 1983;81:613-8.

12. DeJong JW, van der Meer $\mathrm{P}$, van Loon $\mathrm{H}$, et al. Adenosine as an adjunct to potassium cardioplegia: effect on function, energy metabolism, and electrophysiology. J THORAC CARDIOVASC SURG 1990;100:445-54.

13. Sommers KE, Ohkado A, Simplaceanu E, Koretsky A, Ho C, del Nido PJ. The role of magnesium in postischemic cardiac dysfunction. Surgery 1992;112:159-65.

14. Harmsen E, De Tombe P, De Jong JW. Simultaneous determination of myocardial adenine nucleotides and creatine phosphate by high-performance liquid chromatography. J Chromatogr 1982;230:131-6.

15. Nayler.WG, Slade A, Williams EMV, Yepez CE. Effect of prolonged beta-adrenergic blockade on heart weight and ultrastructure in young rabbits. $\mathrm{Br} \mathrm{J}$ Pharmacol 1980; 68:363-71.

16. Reimer KA, Jennings RB. Energy metabolism in the reversible and irreversible phases of severe myocardial ischemia. Acta Med Scand 1981;651:19-27.

17. Kobayashi K, Neely JR. Control of maximum rates of glycolysis in rat cardiac muscle. Circ Res 1979;44:16675 .

18. Neely JR, Morgan HE. Relationship between carbohydrate and lipid metabolism and the energy balance of heart muscle. Ann Rev Physiol 1974;36:413-59.

19. Pierce GN, Philipson KD. Binding of glycolytic enzymes to sarcolemmal and sarcoplasmic reticulum membranes. J Biol Chem 1985;260:6862-70.

20. Jeremy RW, Ambrosio G, Pike MM, Jacobus WE, Becker LC. The functional recovery of post-ischemic myocardium requires glycolysis during early reperfusion. $J$ Mol Cell Cardiol 1993;25:261-76.

21. Kingsley PB, Sako EY, Yang MQ, et al. Ischemic contracture begins when anaerobic glycolysis stops: a 31P-NMR study of isolated rat hearts. Am J Physiol 1991;261:H46978.

22. Grace AA, Kirschenlohr HL, Metcalfe JC, et al. Regulation of intracellular $\mathrm{pH}$ in the perfused heart by external $\mathrm{HCO}_{3}-$ and $\mathrm{Na}^{+}-\mathrm{H}^{+}$exchange. Am J Physiol 1993; 265:H289-98

23. Bretschneider HJ. Myocardial protection. Thorac Cardiovasc Surg 1980;28:295-302.

24. Tait GA, Booker PD, Wilson GJ, Coles JG, Steward DJ, MacGregor DC. Effect of multidose cardioplegia and cardioplegic solution buffering on myocardial tissue acidosis. $\mathbf{J}$ THORAC CARDIOVASC SURG 1982;83:824-9.

25. Jimenez E, del Nido PJ, Feinberg H, Levitsky S. Redistribution of myocardial calcium during ischemia: relationship to onset of contracture. J THORAC Cardiovasc SuRG 1993;105:988-93.

26. Karck M, Vivi A, Tassini M, et al. Optimal level of hypothermia for prolonged myocardial protection assessed by 31P nuclear magnetic resonance. Ann Thorac Surg 1992; $54: 348-51$ 